\title{
Optimization, performance, and application of a pyrolysis- GC/MS method for the identification of microplastics
}

\author{
Hermabessiere Ludovic ${ }^{1}$, Himber Charlotte ${ }^{1}$, Boricaud Beatrice ${ }^{1}$, Kazour Maria 2, 3, Amara Rachid ${ }^{2}$, \\ Cassone Anne-Laure ${ }^{4}$, Laurentie Michel ${ }^{5}$, Paul-Pont Ika ${ }^{4}$, Soudant Philippe ${ }^{4}$, Dehaut Alexandre ${ }^{1}$, \\ Duflos Guillaume 1, *
}

\begin{abstract}
1 ANSES, Lab Securite Aliments, Blvd Bassin Napoleon, F-62200 Boulogne, France.
2 Univ Lille, Univ Littoral Cote Opale, CNRS, UMR 8187,LOG, 32 Ave Foch, F-62930 Wimereux, France.

${ }^{3}$ CNRS, Natl Ctr Marine Sci, POB 534, Batroun, Lebanon.

4 UBO, IFREMER, CNRS, UMR6539,IRD,Lab Sci Environm Marin LEMAR, Inst Uni, Technopole Brest Iroise,Rue Dumont Urville, F-29280 Plouzane, France.

${ }^{5}$ ANSES, Plateforme PAS, Lab Fougeres, 10 B Rue Claude Bourgelat, F-35300 Fougeres, France.
\end{abstract}

* Corresponding author : Ludovic Hermabessiere, email address : guillaume.duflos@anses.fr

\begin{abstract}
:
Plastics are found to be major debris composing marine litter; microplastics (MP, $<5 \mathrm{~mm}$ ) are found in all marine compartments. The amount of MPs tends to increase with decreasing size leading to a potential misidentification when only visual identification is performed. These last years, pyrolysis coupled with gas chromatography/mass spectrometry (Py-GC/MS) has been used to get information on the composition of polymers with some applications on MP identification. The purpose of this work was to optimize and then validate a Py-GC/MS method, determine limit of detection (LOD) for eight common polymers, and apply this method on environmental MP. Optimization on multiple GC parameters was carried out using polyethylene (PE) and polystyrene (PS) microspheres. The optimized Py-GC/MS method require a pyrolysis temperature of $700{ }^{\circ} \mathrm{C}$, a split ratio of 5 and $300{ }^{\circ} \mathrm{C}$ as injector temperature. Performance assessment was accomplished by performing repeatability and intermediate precision tests and calculating limit of detection (LOD) for common polymers. LODs were all below $1 \mu \mathrm{g}$. For performance assessment, identification remains accurate despite a decrease in signal over time. A comparison between identifications performed with Raman micro spectroscopy and with Py-GC/MS was assessed. Finally, the optimized method was applied to environmental samples, including plastics isolated from sea water surface, beach sediments, and organisms collected in the marine environment. The present method is complementary to $\mu$-Raman spectroscopy as Py-GC/MS identified pigment containing particles as plastic. Moreover, some fibers and all particles from sediment and sea surface were identified as plastic.
\end{abstract}




\section{Graphical abstract}

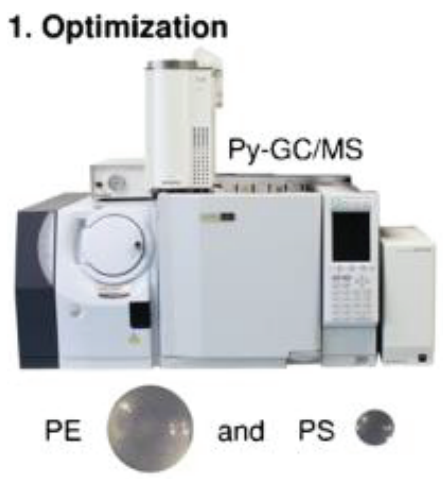

Pyrolysis temperature: $700^{\circ} \mathrm{C}$

Split ratio: 5

Injector temperature: $300^{\circ} \mathrm{C}$

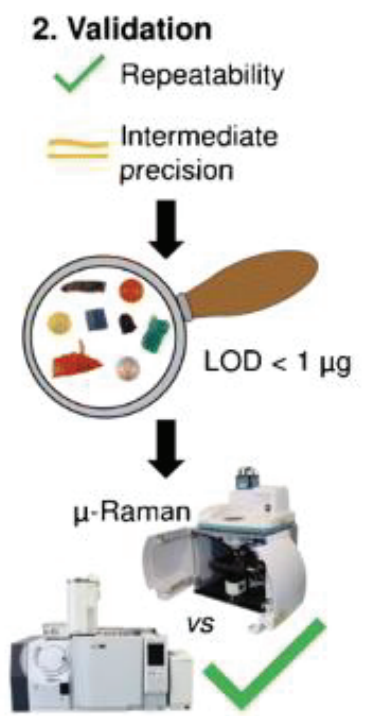

Keywords : Microplastics, Pyrolysis, Gas chromatography, Method, Environmental samples 


\section{Introduction}

Plastic is a commonly used material as it is inexpensive, strong, lightweight, and easy to manufacture [1]. Plastic production increased from the 1950's and reached 335 million metric tons in 2016 [2]. Due to waste management issues and incivilities, it has been estimated that 5 to 12 million plastic particles end up in Oceans in 2010 [3]. Low estimates predicted that floating marine plastic weight between 70,000 and 270,000 tons [4-6], thus, potentially representing more than 51 trillion plastic pieces in Oceans [6].

Microplastics (MP) are plastic particles smaller than $5 \mathrm{~mm}$ in their longest size [7]. To date, multiple studies are carried out to quantify MP in sediments, in water column, and in organisms from both freshwater and marine environments $[8,9]$. For large MP (1-5 mm) [10] and macroplastic $(>5 \mathrm{~mm}$ ), visual identification relying on physical characteristics is possible but the proportion of misidentification grows with decreasing particles size [11]. However, some studies still do not perform any characterization of MP based on their chemical composition [12]. Additionally, as plastic materials include a large variety of polymers, more than 5,000 grades [13], chemical identification is now mandatory to ensure the accuracy of collected pollution data [14]. Raman and Fourier-Transform Infrared (FTIR) spectroscopies are the most common techniques employed to identify polymer types of MP [15]. Furthermore, the use of imaging techniques coupled to spectroscopic approaches allows automatization of MP identification [16-18]. In addition to spectroscopic methods, another type of chemical identification is thermal analysis [12]. Pyrolysis-Gas Chromatography coupled with Mass Spectrometry (Py-GC/MS) is one of the thermal analysis techniques used to identify MP polymers. Py-GC/MS has been used to identify MP from different matrix based on their thermal degradation products [19-25]. Furthermore, Py-GC/MS allows the analysis of a whole MP particle in contrast with Raman or FTIR (in reflection mode) which 
only analyze the surface of the MP particle being sensitive to interference caused by additives such as pigments [26-28], for example.

To date, studies using Py-GC/MS to identify the polymeric composition of MP document neither the method development nor the assessment of its performance. Some authors stated that Py-GC/MS is only feasible with MP $>500 \mu \mathrm{m}[29,30]$ even if so far, $100 \mu \mathrm{m}$ is the smallest size of an isolated MP that has been identified [19]. Recently, particles smaller than 1 $\mu \mathrm{m}$, referred as nanoplastics by the authors, have been identified as plastics based on PyGC/MS and statistical approaches in bulk samples from the North Atlantic Subtropical Gyre [31].

The purpose of this work was fourfolds: (i) optimize a Py-GC/MS method to accurately identify polymer of MP, (ii) assess the performance of the Py-GC/MS approach, (iii) compare identifications with samples already identified by $\mu$-Raman and (iv) apply this technique to environmental samples.

\section{Material and methods}

\subsection{Reference material}

Microspheres with calibrated size ranges were purchased for the Py-GC/MS optimization method. Polyethylene (PE) (180-212 $\mu \mathrm{m}$; reference: CPMS-0.96 180-212um) and Poly(Methyl Methacrylate) (PMMA) (180-212 $\mu \mathrm{m}$; reference: PMMAMS-1.2 180-212um) microspheres were acquired from Cospheric LLC (Santa Barbara, USA) and Polystyrene (PS) (106-125 $\mu \mathrm{m}$; reference: 198241) from Polysciences Europe GmbH (Hirschberg an der Bergstrasse, Germany). For the calculation of the LOD, other polymers were bought from Goodfellow (Lille, France) including filaments of polycaprolactam (PA-6), polyethylene 
93 terephthalate (PET) and polypropylene (PP) and fragments of polycarbonate (PC) and 94 unplasticized polyvinyl chloride (uPVC).

95 For all polymers, characteristic compounds are presented in Table 1 (see Electronic 96 Supplementary Material Figure S1 to S8) and were choose according to their 97 representativeness for polymer identification, their relative intensity, and in comparison with 98 the literature $[22,32,33]$.

99 
Table 1 Polymer related pyrogram information

\begin{tabular}{|c|c|c|c|}
\hline Polymer & Characteristic compound $^{\mathrm{a}}$ & $\mathrm{LRI}^{\mathrm{b}}$ & Indicator ion $(\mathrm{m} / \mathrm{z})$ \\
\hline \multirow{8}{*}{$\mathrm{PE}$} & 1-Nonene (C9) & 893 & $83 ; 97$ \\
\hline & 1-Decene (C10) & 993 & $83 ; 97$ \\
\hline & 1-Undecene (C11) & 1093 & $83 ; 97$ \\
\hline & 1-Dodecene (C12) & 1192 & $83 ; 97$ \\
\hline & 1-Tridecene $(\mathrm{C} 13)$ & 1292 & $83 ; 97$ \\
\hline & 1-Tetradecene (C14) & 1392 & $83 ; 97$ \\
\hline & 1-Pentadecene (C15) & 1492 & $83 ; 97$ \\
\hline & 1-Hexadecene (C16) & 1578 & $83 ; 97$ \\
\hline \multirow{2}{*}{ PS } & Styrene & 898 & $78 ; 104$ \\
\hline & 3-butene-1,3-diyldibenzene (styrene dimer) & 1733 & $91 ; 208$ \\
\hline PMMA & Methyl methacrylate & 743 & $41 ; 69 ; 100$ \\
\hline PP & 2;4-dimethyl-1-heptene & 846 & 70 \\
\hline PA-6 & E-caprolactam & 1274 & 113 \\
\hline \multirow{6}{*}{$\mathrm{PC}$} & Phenol & 980 & $66 ; 94$ \\
\hline & $\mathrm{p}$-Cresol & 1075 & $77 ; 107$ \\
\hline & p-Ethylphenol & 1168 & $107 ; 122$ \\
\hline & p-Vinylphenol & 1217 & $91 ; 120$ \\
\hline & p-Isopropenylphenol & 1304 & $119 ; 134$ \\
\hline & Bisphenol A & 2088 & $213 ; 228$ \\
\hline \multirow{5}{*}{ PET } & Benzene & 770 & $52 ; 78$ \\
\hline & Acetophenone & 1076 & $51 ; 77 ; 105$ \\
\hline & Vinyl benzoate & 1145 & $52 ; 77 ; 105$ \\
\hline & Benzoic acid & 1178 & $77 ; 105 ; 122$ \\
\hline & Divinyl terephthalate & 1574 & $104 ; 175$ \\
\hline \multirow{7}{*}{ uPVC } & Benzene & 770 & $52 ; 78$ \\
\hline & Toluene & 782 & 91 \\
\hline & Styrene & 898 & $78 ; 104$ \\
\hline & Indene & 1059 & 116 \\
\hline & Naphthalene & 1206 & 128 \\
\hline & 2-methylnaphthalene & 1320 & $115 ; 142$ \\
\hline & 1-methylnaphthalene & 1340 & $115 ; 142$ \\
\hline
\end{tabular}




\subsection{Sample preparation}

102 Each particle was selected based on its size $(c a .200 \mu \mathrm{m})$ under a SZ61 stereomicroscope

103 (Olympus, Rungis, France) and then introduced into an analysis cup (Frontier-Lab,

104 Fukushima, Japan) for Py-GC/MS analysis. All analysis cup used in this work were brand

105 new cups visually controlled prior to analysis to detect any possible contamination.

\section{$106 \quad$ 2.3. Size and weight estimation}

107 In order to estimate the size of the particle, a photograph was taken with a scale bar using a

108 DP21 camera (Olympus, Rungis, France) mounted on the stereomicroscope. The size in pixel

109 of the particle was recorded using GIMP 2 software (2.8.16). Then, the maximum size in $\mu \mathrm{m}$

110 of the particle was calculated using the scale bar. For each particle, the volume $\left(\mathrm{cm}^{3}\right)$ was

111 estimated using different formula (1), (2) or (3), where D corresponds to the diameter, L to the

112 length and S to the side size (see Electronic Supplementary Material Weight estimation). The

113 volume was then multiplied by the density $\left(\mathrm{g} / \mathrm{cm}^{3}\right)$ of the polymer to obtain the estimated 114 weight.

$$
\begin{aligned}
& \text { (1) Microsphere volume }=\frac{4}{3} \times \pi \times\left(\frac{D}{2}\right)^{3} \\
& \text { (2) Filament volume }=\left(\frac{D}{2}\right)^{2} \times \pi \times L \\
& \text { (3) Fragment volume }=S^{2} \times L
\end{aligned}
$$

\section{$115 \quad$ 2.4. Method optimization}

\section{2.4.1. Initial Py-GC/MS method}

117 The hereafter called "initial method" was described by Dehaut et al. [35]. Briefly, the analysis

118 cup containing the plastic was placed on the AS-1020E autosampler of an EGA/PY-3030D

119 device (Frontier Lab, Fukushima, Japan). Samples were pyrolysed at $600{ }^{\circ} \mathrm{C}$ for $1 \mathrm{~min}$. 
120 Pyrolysis products were injected with a split of 20, on a GC-2010 device (Shimadzu, Noisiel,

121 France) equipped by a RXi-5ms ${ }^{\circledR}$ column $(60 \mathrm{~m}, 0.25 \mathrm{~mm}, 25 \mu \mathrm{m}$ thickness) (Restek, Lisses,

122 France). Temperatures of the pyrolyzer interface and the injection port were both set at 300

$123{ }^{\circ} \mathrm{C}$. Helium was used as a carrier gas with a linear velocity of $40 \mathrm{~cm} / \mathrm{s}$. The initial oven

124 program, called here after program $\mathbf{0}$, was set as follows: $40{ }^{\circ} \mathrm{C}$ for $2 \mathrm{~min}$, then increase to

$125320^{\circ} \mathrm{C}$ at $20^{\circ} \mathrm{C} / \mathrm{min}$, maintained for $14 \mathrm{~min}$. Mass spectra were obtained by a Shimadzu

126 QP2010-Plus mass spectrometer. Interface temperature was set at $300{ }^{\circ} \mathrm{C}$, ion source 127 temperature was set at $200{ }^{\circ} \mathrm{C}$, ionization voltage was set at $70 \mathrm{eV}$, and a mass range from 33

128 to $500 \mathrm{~m} / \mathrm{z}$ was scanned at $2000 \mathrm{~Hz}$.

129 As a primary attempt, polymer identification was realized using total ion pyrogram (TIC)

130 which was firstly identified using F-Search software 4.3, querying pyrograms against Frontier

131 Lab's database, and our own database containing pre-established pyrograms with plastic 132 samples. Identification was established based on the similarity percentage (minimum value of $13380 \%$ ) between average mass spectra on the whole chromatogram. Our home-made database 134 was created using our "initial method" and the optimized Py-GC/MS method on plastic 135 references from Goodfellow (Lille, France). Plastic references used for our home-made 136 database included: PE, PS, PP, PET, PA-6, PC, PMMA and uPVC.

137 When identification was not possible after primary attempt, a classical GC/MS treatment was 138 performed. Peaks of pyrograms were integrated and compared with available literature [32] or 139 characteristic compounds (Table 1), single peak identification being carried out using NIST08 140 database and LRI. 


\subsubsection{Pyrolysis temperature}

142 Optimization of the pyrolysis temperature was carried out using the initial pyrolysis method.

143 The impact of pyrolysis temperature was determined using five replicate of PE microspheres.

144 Three additional pyrolysis temperatures were tested: 500, 700 and $800^{\circ} \mathrm{C}$ for $1 \mathrm{~min}$.

\section{2.4.3. GC oven temperature program}

146 In addition to Program 0, two others temperature programs were tested. Program 1 was set 147 as follow: $40{ }^{\circ} \mathrm{C}$ for $2 \mathrm{~min}$, then increase to $200{ }^{\circ} \mathrm{C}$ at $15^{\circ} \mathrm{C} / \mathrm{min}$ followed by a second 148 increase to $300{ }^{\circ} \mathrm{C}$ at $10{ }^{\circ} \mathrm{C} /$ min maintained for 2 min. Program 2 was set as follow: $40{ }^{\circ} \mathrm{C}$ 149 for $2 \mathrm{~min}$, then increase to $261{ }^{\circ} \mathrm{C}$ at $13{ }^{\circ} \mathrm{C} / \mathrm{min}$ followed by a second increase to $300{ }^{\circ} \mathrm{C}$ at 6 $150{ }^{\circ} \mathrm{C} / \mathrm{min}$ maintained for $2 \mathrm{~min}$. Except pyrolysis temperature was set at $700{ }^{\circ} \mathrm{C}$ the optimal 151 temperature for $1 \mathrm{~min}(c f .3 .1 .1)$, oven program was the unique parameter modified in this 152 part, other parameters were conserved as those of the initial method. The impact of GC oven 153 temperature program on resolution was determined using PE microspheres. Here the 154 resolution was only used to assess the separation between PE alkene and alkadiene. The 155 resolution of alkenes (from $\mathrm{C}_{9}$ to $\mathrm{C}_{16}$ ) was used to evaluate each program performance. 156 Resolution was calculated by the Shimadzu GC-MS postrun analysis software using (4),

157 where $T_{r}$ corresponds to the retention time of the considered peak (Alkene), $T_{r p}$ to the 158 retention time of the previous peak (Alkadiene), $\mathrm{W}$ to the width of the considered peak and $159 \mathrm{~W}_{\mathrm{p}}$ to the width of the previous peak:

$$
\text { (4) } \text { Resolution }=2 \times \frac{T_{r}-T_{r p}}{W+W_{p}}
$$

160 Five replicates were performed per programs. 


\subsubsection{Injector temperature and split ratio}

162 Optimization on the split ratio and injector temperature was performed using PE and PS 163 microspheres. Here, PS was used in addition to PE as this polymer exhibits only a few

164 degradation products after pyrolysis (Table 1). Three split ratios (50, 20 and 5) and three 165 injector temperatures $\left(280,300\right.$ and $\left.320{ }^{\circ} \mathrm{C}\right)$ were applied, resulting in nine distinct 166 combinations. For all combinations, pyrolysis temperature and GC oven program were set 167 following the previous optimization steps, others parameters were conserved as those 168 described for the initial method (cf. 2.4.1). For each combination, five microspheres of PE and 169 PS were analyzed.

\subsection{Method performance evaluation}

171 Split ratios were adjusted to ensure that no saturation of the mass spectrum occured. To do so, 172 split ratio was set at 5 for PE microspheres, particles identified by $\mu$-Raman spectroscopy, and 173 unknown particles injection, whereas for PMMA and PS microspheres injection, a split of 50 174 was chosen.

\section{$175 \quad$ 2.5.1. Repeatability and intermediate precision}

176 For repeatability and intermediate precision, respectively ten and five microspheres of the

177 three polymers were pyrolysed and the Relative Standard Deviation (RSD) (5) was calculated 178 for each characteristic peak according to ISO 5725-3 [36] where $s$ is the standard deviation 179 and $m$ is the mean:

$$
\text { (5) } R S D(\%)=\frac{s}{m} \times 100
$$

180 Intermediate precision was assessed over time with pyrolysis occurring at 3,4 and 6 weeks

181 after repeatability experiences. The method is considered valid if RSD is below $20 \%$ for

182 repeatability and intermediate precision. Moreover, polymer identification of the particles was 183 performed as previously described (cf. 2.4.1) to obtain qualitative data. 
185 Limit of detection was calculated according to Caporal-Gautier et al. [37]. First, ten analysis 186 cups without plastic, hereafter referred as "blank", were pyrolysed. For each blank and at the 187 retention time of each characteristic peak of the eight used polymers (Table 1), the maximum 188 height was determined over a time interval equal to 20 times the full width at half maximum 189 (FWHM), this area is called $\mathrm{H}_{20 \mathrm{FWHM}}$. Interval surrounds the retention time of each peak with

190 the retention time being the central point of the time range. Five particles were pyrolysed for 191 each polymer. A response factor (R) (6) was calculated: "Weight" corresponds to the mean 192 the average calculated weight and "Height" corresponds to the mean height of the 193 characteristic peak for the five particles:

$$
\text { (6) Response factor }(R)=\frac{\text { Weight }}{\text { Height }}
$$

194 Finally, for each polymer LOD were calculated as follow:

$$
\text { (7) Limit of Detection }(L O D)=3 \times R \times H_{20 \mathrm{FWHM}}
$$

\section{$195 \quad$ 2.6. Method comparison}

\subsubsection{Sampling}

197 Unknown plastic particles were first analysed by $\mu$-Raman and then by Py-GC/MS before 198 identification to be compared. Comparison of the identification of unknown plastic particles

199 obtained after $\mu$-Raman spectroscopy and Py-GC/MS was performed. To assess methods 200 comparison, fifty plastic particles hand sampled on a local beach (Equihen Plage, France $\left.201 \quad 50^{\circ} 39^{\prime} 51.08^{\prime \prime} \mathrm{N}, 1^{\circ} 34^{\prime} 17.94^{\prime \prime} \mathrm{E}\right)$ were used.

\subsubsection{Identification by $\mu$-Raman and Py-GC/MS}

203 For $\mu$-Raman analysis, each particle was analyzed with an XploRA PLUS V1.2 (HORIBA 204 Scientific, France SAS) equipped with two lasers of 785 and $532 \mathrm{~nm}$ wavelength. First, plastic 
particles were analyzed with laser wavelength set at $785 \mathrm{~nm}$ over a range of 50 to $3,940 \mathrm{~cm}^{-1}$ with a $\times 10(\mathrm{NA}=0.25 ; \mathrm{WD}=10.6 \mathrm{~mm})$ or $\times 100(\mathrm{NA}=0.9 ; \mathrm{WD}=0.21 \mathrm{~mm})$ objective (Olympus, France). If identification with the $785 \mathrm{~nm}$ laser was not successful, particles were secondly analyzed with a laser wavelength set at $532 \mathrm{~nm}$ over a range of 50 to $4,000 \mathrm{~cm}^{-1}$ with a $\mathrm{x} 10$ or x100 objective. The experimental conditions (integration time, accumulation, laser power) were adapted to limit fluorescence and increase the spectral quality of the analyzed particles.

211 Polymer identification was carried out using spectroscopy software (KnowItAll, Bio-Rad) and our own database containing pre-established polymers spectra. Identification was considered correct if Hit Quality Index (HQI) was above 80 (ranging from 0 to 100). If identification of a

214 particle was not successful after $\mu$-Raman spectroscopy, the particle was then included in the 215 section 2.7.

216 For Py-GC/MS, a piece of each particle was cut to the smallest possible size and prepared as 217 indicated in section 2.2. Pyrolysis-GC/MS was realized as described above (cf. 2.5).

\subsection{Application: identification of unknown particles}

\subsubsection{Sampling}

Application of the Py-GC/MS was performed using particles collected on a beach, extracted

221 from bivalves and collected on sea surface waters.

222 Ten particles, collected by hand on a local beach, including 4 particles identified as pigment 223 and 6 particles unidentified (cf. 3.3) were analyzed using Py-GC/MS.

224 Mussels (Mytilus edulis) and cockles (Cerastoderma edule) were respectively sampled during 225 morning low tides at Le Portel, France $\left(50^{\circ} 42^{\prime} 30.02^{\prime \prime}\right.$ N, $1^{\circ} 33^{\prime} 34.43$ 'E) on 10/29/2015 and at 226 Baie d'Authie, France $\left(50^{\circ} 22^{\prime} 17.22^{\prime \prime N}, 1^{\circ} 35^{\prime} 4.8^{\prime} \mathrm{E}\right)$ on $11 / 15 / 2015$. Bivalves were then 227 dissected, digested, and filtered using the method of Dehaut et al, [35]. Particles resembling 228 plastic found in bivalves were extracted under a stereomicroscope using tweezers and 
submitted to $\mu$-Raman identification using an LabRam HR800 (HORIBA Scientific,

230 Villeneuve d'Ascq, France) following a methodology adapted from Frère et al, [16]. Here, 16

231 particles from bivalves, previously identified as pigments containing particles, and 10

232 unknown particles in form of fibers were analyzed. Finally, 24 unknown particles collected in

233 sea-surface trawls from the bay of Brest, as described by Frère et al. [38], were used for

234 identification by Py-GC/MS.

\subsubsection{Identification by Pyrolysis-GC/MS}

236 In total, sixty particles with no previous polymer identification were analyzed. For Py237 GC/MS, a piece of each particle was cut to the smallest size possible and prepared as 238 indicated in section 2.2. Pyrolysis-GC/MS was realized as described above (cf. 2.5). Results 239 will be present and discuss according to the following categories: pigments containing 240 particles, fibers and others particles.

\section{$241 \quad$ 2.8. Statistical analyses}

242 All statistical analyses with an exception for RSD calculation were performed using R (3.4.0)

243 [39]. For method optimization, including verification of estimated size of microspheres used, 244 normality and homoscedasticity of the distribution hypothesis were carefully verified before 245 performing ANOVA. Assuming one of the hypothesis was not verified, a Kruskal-Wallis test 246 was carried out. Kruskal-Wallis tests were followed by a conservative post-hoc test using the 247 Fisher's least significant difference (LSD) criterion and Bonferroni correction. Post-hoc tests 248 were performed using the agricolae package (1.2-7) [40]. All results are expressed as a mean $249 \pm 2$ standard error (S.E), representing the $95 \%$ confidence interval (95\% CI). Differences were 250 considered significant when $p$-value $<0.05$. On bar charts, two different letters illustrates 251 significantly different value with a $95 \%$ CI. 


\section{Results and discussion}

253 All procedural blank, i.e analysis cup without sample, presented no sign of contamination by

254 pyrolytic products of synthetic polymers.

\subsection{Method optimization}

\subsubsection{Pyrolysis temperature}

PE microspheres size (204 to $214 \mu \mathrm{m}$ ) used for optimizing the pyrolysis temperature were not

significantly different for each tested temperatures (One-way ANOVA, $\mathrm{p}>0.05$ ). Pyrolysis temperature $\left(500,600,700\right.$ and $\left.800{ }^{\circ} \mathrm{C}\right)$ had a significant impact on the peaks areas of $\mathrm{PE}$ (Fig. 1). On the one hand, for the eight characteristic compounds of PE, peaks areas rises when the pyrolysis temperature increase from 500 to $700{ }^{\circ} \mathrm{C}$ but on the other hand at $800{ }^{\circ} \mathrm{C}$, peaks areas slightly decreased (Fig. 1). Moreover, significant difference of areas were recorded for characteristic compounds of PE (Kruskal-Wallis, $\mathrm{p}<0.05$ ). Areas were 264 significantly higher at $700{ }^{\circ} \mathrm{C}$ in comparison with areas at $500{ }^{\circ} \mathrm{C}$ (Kruskal-Wallis followed by post-hoc, $\mathrm{p}<0.05-$ Fig. 1). Significant differences between areas at 600 and $700{ }^{\circ} \mathrm{C}$ were observed for 1-Nonene, 1-Decene, 1-Undecene, 1-Dodecene, and 1-Tridecene (KruskalWallis followed by post-hoc, $\mathrm{p}<0.05$ - Fig. 1). However, no significant difference was observed between 500 and $600{ }^{\circ} \mathrm{C}$, between 700 and $800{ }^{\circ} \mathrm{C}$, and between 600 and $800{ }^{\circ} \mathrm{C}$ for

269 all 8 characteristics compounds (Kruskal-Wallis followed by post-hoc, $p<0.05-$ Fig. 1 ). At

$270800{ }^{\circ} \mathrm{C}$, pyrograms of PE microspheres were not all typical with the presence of unknown compounds at the beginning of the pyrogram which lead to identification with a percentage

272 below $80 \%$ (see Electronic Supplementary Material Figure S9). As $700{ }^{\circ} \mathrm{C}$ demonstrated

273 higher areas for characteristic compounds of PE with typical and clearly identified pyrograms;

274 optimal pyrolysis was then set at $700{ }^{\circ} \mathrm{C}$. 

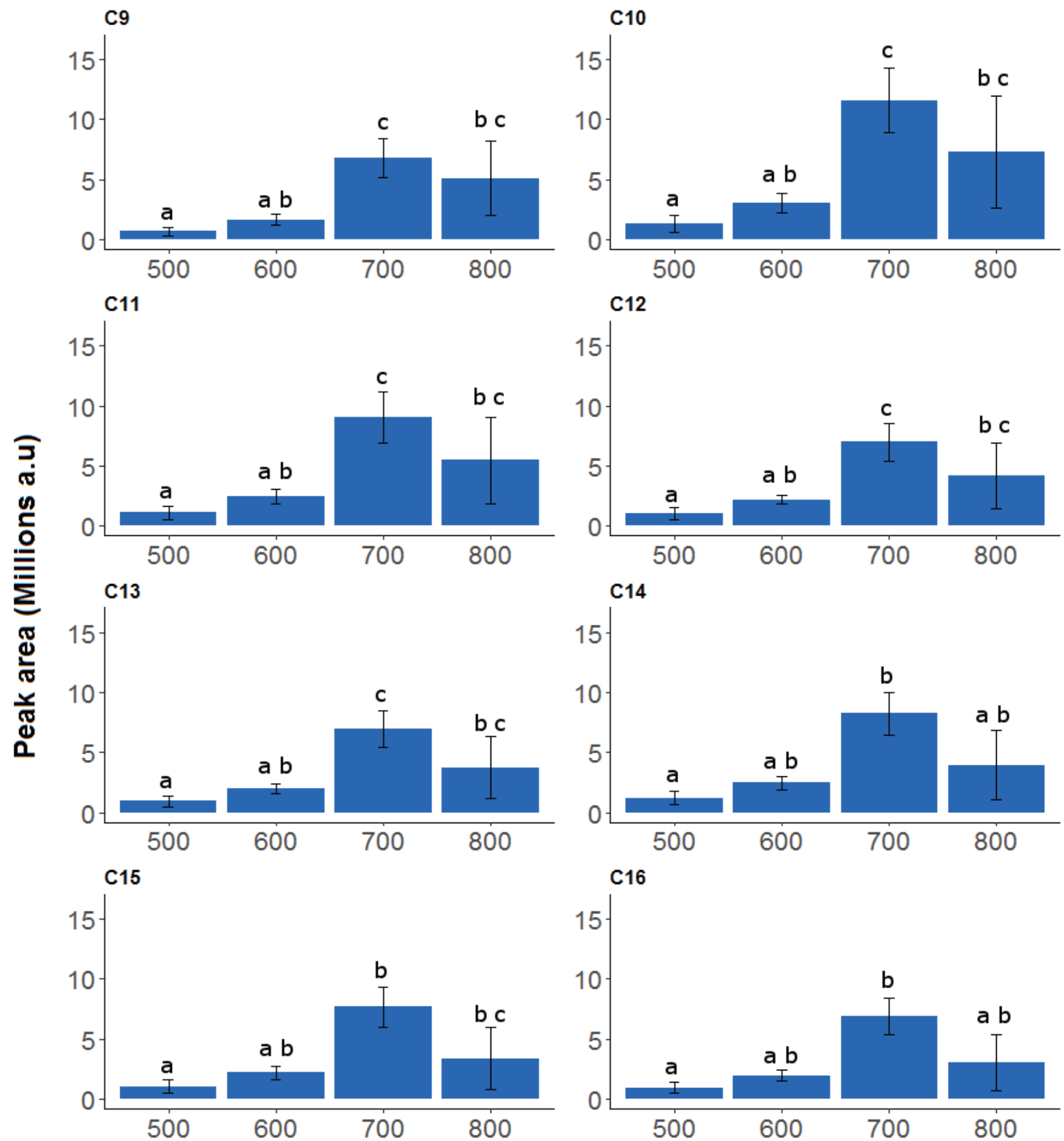

Pyrolysis temperature (in ${ }^{\circ} \mathrm{C}$ )

Fig. 1 Peaks areas (Arbitrary Unit) depending on the Pyrolysis temperature $\left(\right.$ in ${ }^{\circ} \mathrm{C}$ ) for eight characteristic compounds of PE. Values as expressed as mean $\pm 95 \%$ confidence interval. Letters correspond to the differences after post-hoc test using the Fisher's least significant difference with Bonferroni correction. C9: 1-Nonene; C10: 1-Decene; C11: 1-Undecene; C12: 1-Dodecene; C13: 1-Tridecene; C14: 1Tetradecene; C15: 1-Pentadecene; C16: 1-Hexadecene

Regarding the literature, studies generally used a pyrolysis temperature of $700{ }^{\circ} \mathrm{C}[19-21,23$, $31,33]$ while others used lower temperature such as $550{ }^{\circ} \mathrm{C}[24], 590^{\circ} \mathrm{C}$ [22], $600{ }^{\circ} \mathrm{C}[32,35]$ or $650^{\circ} \mathrm{C}$ [25]. As presented in this work, pyrolysis temperature had a clear impact on the signal of the pyrolytic products of PE and could potentially impact identification for small 
particles. Additionally, pyrolysis at a temperature greater than or equal to $800{ }^{\circ} \mathrm{C}$ had a

286 negative effect on PE pyrolytic products. Indeed, the signal was decreased and the polymer

287 identification was not possible with our software due to the presence of a large interfering 288 peak at the beginning of the pyrogram (see Electronic Supplementary Material Figure S9).

289 Moreover, as indicated by Kusch [33], pyrolysis temperature could also impact the generated 290 pyrolysis products. Here for PC, PET, and uPVC some pyrolysis products were different from 291 those recorded with the initial Py-GC/MS method [35] and from a reference book [32]. Such 292 differences could prevent identification of these polymers as many libraries were obtained 293 after pyrolysis at $600{ }^{\circ} \mathrm{C}$. However, the use of our own database create with pyrolysis 294 temperature set at $700{ }^{\circ} \mathrm{C}$ allow accurate polymer identification.

\subsubsection{GC oven temperature program}

296 PE microspheres size (197 to $226 \mu \mathrm{m}$ ) used for the optimization of the GC oven temperature 297 program were not significantly different for each tested conditions (One-way ANOVA, $298 \mathrm{p}>0.05)$. For all characteristic compounds of PE and for the three GC oven temperature 299 programs, resolution was above 1.5 (see Electronic Supplementary Material Figure S10) 300 which is acceptable [41]. Significant differences in resolution were observed for all peaks of 301 PE (Kruskal-Wallis, $\mathrm{p}<0.01$ ) depending on the used GC oven temperature program. 302 Moreover, program 2 demonstrated higher resolution in comparison with program 0 and 1

303 (Kruskal-Wallis followed by Fisher's LSD with Bonferroni correction, $\mathrm{p}<0.05$ - see 304 Electronic Supplementary Material Figure S10). Here, resolution and peak separation was 305 higher when ramping temperature decrease. Higher peak resolution could be useful for 306 manual identification of peaks, if primary attempt using F-Search software is not conclusive. 307 Program 2 was then applied to perform separation of pyrolysis compounds using the GC 308 system. 


\subsubsection{Injector temperature and split ratio}

310 PS (110 to $136 \mu \mathrm{m})$ and PE (188 to $223 \mu \mathrm{m})$ microspheres size used for the optimization on

311 split ratio and injection temperature were not significantly different for each tested conditions

312 (One-way ANOVA, $\mathrm{p}>0.05$ ). For all characteristic compounds of PE, areas significantly

313 decreased with the increase of split ratio (Kruskal-Wallis followed post-hoc, $p<0.05-$ Fig. 2).

314 Moreover, no significant difference in peaks areas were observed at split ratio of 20 and 50

315 depending on the injector temperature used (Kruskal-Wallis, $\mathrm{p}>0.05$ ). However, it should be 316 noticed that significant differences between injection at 280,300 , and $320^{\circ} \mathrm{C}$ were observed

317 using a split ratio of 5 for all characteristic compounds (Kruskal-Wallis followed by post-hoc,

$318 \mathrm{p}<0.05-$ Fig. 2). Indeed, with the exception of 1-Nonene, the highest peaks areas were 319 obtained when injector temperature was set at $300^{\circ} \mathrm{C}$ with a split ratio of 5 (Fig. 2).
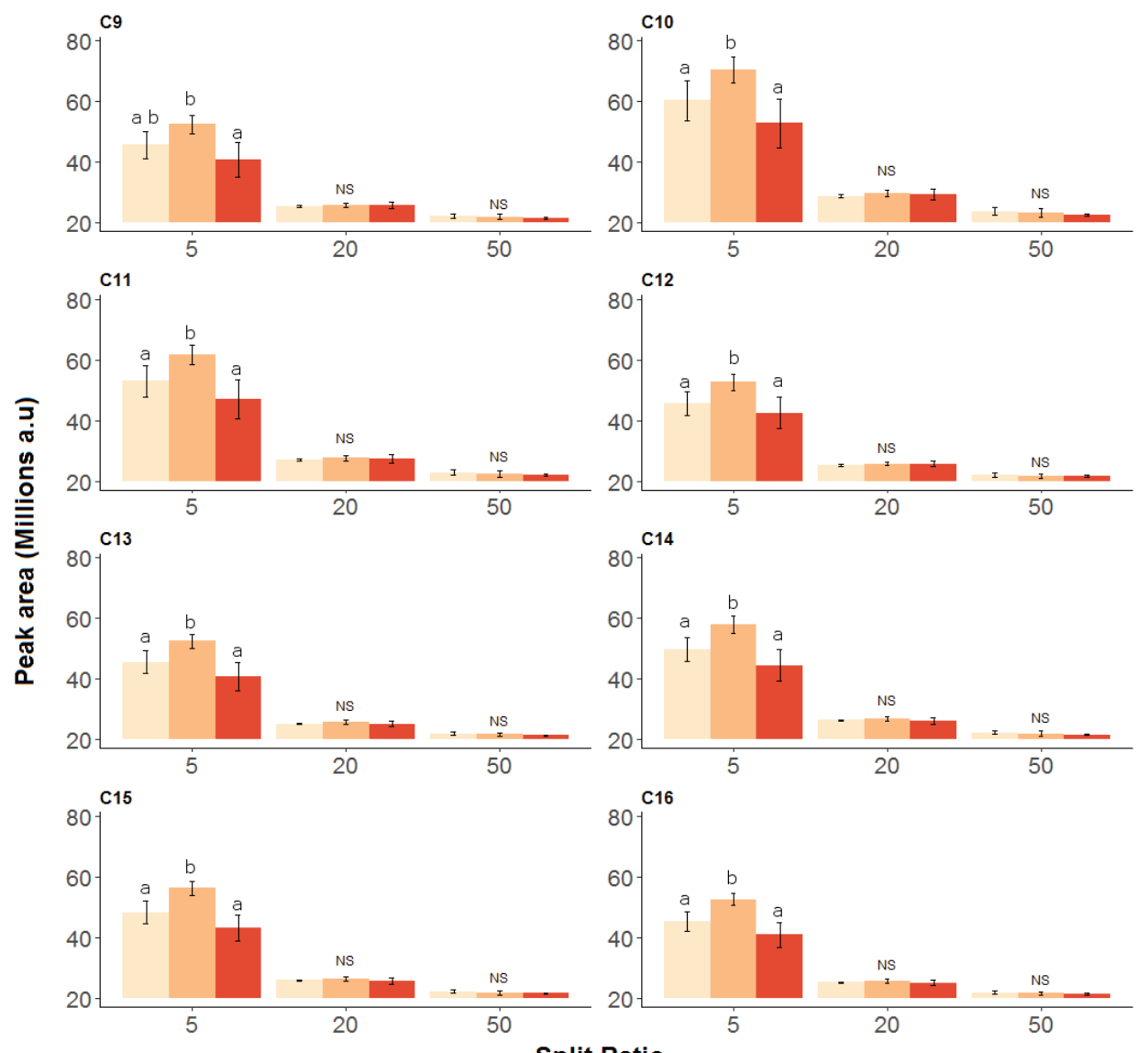

Split Ratio

Fig. 2 Peaks areas (Arbitrary Unit) depending on the split ratio and injection temperature for 8 characteristics compounds of PE. Values as expressed as mean $\pm 95 \%$ confidence interval. Letters 
correspond to the differences after post-hoc test using the Fisher's least significant difference with Bonferroni correction and NS stand for non-significant. C9: 1-Nonene; C10: 1-Decene; C11: 1-Undecene; C12: 1-Dodecene; C13: 1-Tridecene; C14: 1-Tetradecene; C15: 1-Pentadecene; C16: 1-Hexadecene

For PS, as for PE, increasing split ratio decreased peaks areas (Kruskal-Wallis, $\mathrm{p}<0.01-$ see Electronic Supplementary Material Figure S11). For styrene, at a split ratio of 5, areas were significantly different between $320^{\circ} \mathrm{C}$ and the others temperatures (Kruskal-Wallis followed by post-hoc, $\mathrm{p}<0.05$ - see Electronic Supplementary Material Figure S11) and at a split ratio of 20, areas were significantly different between 280 and $320{ }^{\circ} \mathrm{C}$ (Kruskal-Wallis followed by post-hoc, $\mathrm{p}<0.05$ - see Electronic Supplementary Material S11). However, no significant difference were observed for area values at a split ratio of 50 between injector temperatures (Kruskal-Wallis, $\mathrm{p}<0.05$ ). No significant difference were observed for styrene dimer areas between injector temperatures at each split ratio (Kruskal-Wallis, $\mathrm{p}>0.05$ ).

As split ratio is inversely related to the amounts of sample entering the column, such results were expected. Generally, studies using Py-GC/MS to identify MP used low split ratio to increase analyte signal. Indeed, splitless mode was used for injection by severals authors [19$21,24]$ while split ratio of 10 [25] or 15 [22] were used by others authors. In several works, split ratio was adapted depending on the weight of the particle to identify [24, 31]. Indeed, Ter Halle et al, [31] used a split ratio of 5 for nanoplastics (25 $\mathrm{mg}$ of lyophilizate), 10 for micrometric plastic (particle on filter) and 100 for meso and microplastics and commercial plastics (approximately $10 \mu \mathrm{g}$ ). In addition, in their work Hendrickson et al, [24] used the splitless mode for particles $<20 \mu \mathrm{g}$ and a split ratio of 100 for particles $>20 \mu \mathrm{g}$. In the others studies few or no information are available on the size or the weight of MP used for Pyrolysis $[19,21,22,25]$. Here, split ratios tested were between 5 and 50 to be around the split ratio used in our previous work [35] and in order to obtain area for PE characteristic peak above a million of arbitrary unit allowing correct identification using the software. With this optimized Py-GC/MS method, split ratio should also be adapted depending on the weight of 
particles. Indeed, for unknown particles smaller than $5 \mu \mathrm{g}$ a split ratio of 5 should be used and

350 for particles heavier than $5 \mu \mathrm{g}$, split ratio should be set at 20. Moreover, injector temperature 351 of $300{ }^{\circ} \mathrm{C}$ in combination with split ratio of 5 had a significant effect on peaks areas for all 352 PE's peaks and for styrene from PS (Fig. 2 \& see Electronic Supplementary Material Figure 353 S11) which could be important to detect small particles. Here an injection temperature set at $354300{ }^{\circ} \mathrm{C}$ was chosen for performance assessment purpose.

355 Globally, method optimization is an important step for the detection and then the 356 identification of MP using Py-GC/MS. Indeed, the higher the signal will be, the higher the 357 probability of identification will be but mass spectrum saturation should be avoided to ensure 358 proper identification. Moreover, MP signal tend to increase with an increasing size of the 359 particle.

\subsection{Method performance evaluation}

\subsubsection{Method repeatability and intermediate precision}

362 PE, PMMA, and PS microspheres used for assessing method repeatability and intermediate 363 precision did not display significant difference in sizes (One-way ANOVA or Kruskal-Wallis, $364 \mathrm{p}>0.05$ ). Firstly, polymer identifications were, over the 6 weeks period, accurate with 365 similarity percentage all above $90 \%$. Identification was successful in all cases and the method 366 could be considered repeatable within a week and precise over the 6 weeks. Concerning the 367 repeatability RSD, values were below $20 \%$ for the characteristic compounds of PE and 368 PMMA and above $20 \%$ for characteristics compounds of PS (Table 2). For styrene dimer, 369 highly variable peak areas were recorded for repeatability test. In addition RSD value above $37020 \%$ for styrene was due to one repetition that presents peak area 1.5 higher in comparison 371 with others replicates. Then, concerning intermediate precision RSD values were above $20 \%$

372 for all characteristics compounds of PE, PS, and PMMA (Table 2). Consequently, the method 
373 is repeatable for PE and PMMA but not precise over time for all the three tested polymers,

374 regarding quantitative data. Depending on when the analysis was performed, a high variation

375 in peak areas was recorded and thus was responsible for high values of RSD. Indeed, at weeks

3761,3 and 4, areas of characteristics peaks were in the same order of magnitude (for an example

377 see see Electronic Supplementary Material Figure S12). However at week 6, an important

378 diminution of the signal was observed (see Electronic Supplementary Material Figure S12)

379 which can cause the high variability in RSD values for method intermediate precision.

380 Finally, despite a decrease over time in peaks areas for characteristic compounds of PE, PS

381 and PMMA, identifications remained exact. This is essential for future use of the optimized

382 Py-GC/MS method to identify MP.

383 Table 2 Relative standard deviation (in \%) for method repeatability $(\mathrm{n}=10)$ and intermediate precision $384(\mathbf{n}=\mathbf{2 0})$ for characteristics compounds of Polyethylene, Polystyrene and Poly(Methyl Methacrylate)

\begin{tabular}{|c|c|c|c|}
\hline Polymer & Characteristic compound & $\begin{array}{c}\text { Repeatability } \\
\text { RSD (\%) }\end{array}$ & $\begin{array}{c}\text { Intermediate } \\
\text { Precision RSD } \\
(\%)\end{array}$ \\
\hline \multirow{8}{*}{ PE } & 1-Nonene & 10,67 & 31.82 \\
\hline & 1-Decene & 9,91 & 31.34 \\
\hline & 1-Undecene & 10,01 & 31.79 \\
\hline & 1-Dodecene & 9,55 & 31.40 \\
\hline & 1-Tridecene & 9,06 & 33.11 \\
\hline & 1-Tetradecene & 8,81 & 30.22 \\
\hline & 1-Pentadecene & 8,98 & 30.88 \\
\hline & 1-Hexadecene & 9,62 & 30.76 \\
\hline \multirow{2}{*}{ PS } & Styrene & 22,47 & 32.57 \\
\hline & 3-butene-1,3-diyldibenzene (styrene dimer) & 48,03 & 49.69 \\
\hline PMMA & Methyl methacrylate & 9,19 & 24.34 \\
\hline
\end{tabular}




\subsubsection{Limit of Detection}

386 The estimated LOD were below $1 \mu \mathrm{g}$ for all tested polymers using the optimized Py-GC/MS 387 (Table 3). Detection of smaller particles of polymers with a few peaks, such as PS or PMMA 388 could be easier compared to PE which presents numerous pyrolysis products.

Table 3 Limit of detection (LOD) for eight common polymer and associate theoretical estimate size of identifiable particle, in the form of sphere, fiber and fragment.

\begin{tabular}{|c|c|c|c|c|}
\hline \multirow[b]{2}{*}{ Polymer } & \multirow[b]{2}{*}{ LOD (in $\mu \mathrm{g}$ ) } & \multicolumn{3}{|c|}{ Theoretical size } \\
\hline & & $\begin{array}{c}\text { Sphere } \\
\text { diameter (in }^{\text {um) }}{ }^{d}\end{array}$ & $\begin{array}{l}\text { Fiber length } \\
\text { (in } \mu \mathrm{m}) \mathrm{d} \text { e }\end{array}$ & $\begin{array}{c}\text { Fragment } \\
\text { length } \underset{\mathrm{f}}{\mathrm{in}} \boldsymbol{\mu \mathrm { m }})\end{array}$ \\
\hline $\mathrm{PE}^{\mathrm{a}}$ & 0.070 & 51.7 & 229.9 & 28.9 \\
\hline $\mathrm{PS}^{\mathrm{a}}$ & 0.003 & 17.7 & 9.2 & 1.2 \\
\hline $\mathrm{PMMA}^{\mathrm{a}}$ & 0.029 & 35.9 & 77.2 & 9.7 \\
\hline PA- $6^{\mathrm{b}}$ & 0.110 & 57.1 & 309.9 & 38.9 \\
\hline $\mathrm{PP}^{\mathrm{b}}$ & 0.027 & 38.6 & 95.5 & 12.0 \\
\hline $\mathrm{PET}^{\mathrm{b}}$ & 0.015 & 27.4 & 34.1 & 4.3 \\
\hline$P C^{c}$ & 0.116 & 35.9 & 77.0 & 9.7 \\
\hline $\mathrm{uPVC}^{\mathrm{c}}$ & 0.592 & 58.7 & 366.6 & 42.3 \\
\hline \multicolumn{5}{|c|}{$\begin{array}{l}{ }^{\mathrm{a}} \text { Polymer used in form of microspheres } ;{ }^{\mathrm{b}} \text { Polymer used in form of filaments; }{ }^{\mathrm{c}} \text { Polymer used in form of } \\
\text { fragments; }{ }^{\mathrm{d}} \text { LOD in size for sphere. fiber and fragment were calculated based on LOD in weight; }{ }^{\mathrm{e}} \\
\text { Calculation made with a diameter of } 20 \mu \mathrm{m} ;{ }^{\mathrm{f}} \text { Calculation made based on a parallelepipoid form with } 50 \mu \mathrm{m} \\
\text { as side size. }\end{array}$} \\
\hline
\end{tabular}

To date, identification of isolated MP using Py-GC/MS was successful for particles with a size down to $100 \mu \mathrm{m}$ [19] and down to $0.4 \mu \mathrm{g}$ [22]. Here, uPVC demonstrated the highest LOD with $0.592 \mu \mathrm{g}$. This could be explained by uPVC fragment form and important density. Indeed, uPVC particles were thick $(\approx 310 \mu \mathrm{m})$ and long (195 to $220 \mu \mathrm{m})$ leading to heavy 396 particles $(>20 \mu \mathrm{g})$ due to its important density $\left(1.4 \mathrm{~g} \mathrm{~cm}^{-3}\right)$ leading to an heavy estimated 397 weight in comparison with other polymers. Globally, polymers with the highest densities, PA6, PC or uPVC, have the highest LOD (Table 3). In the present study, estimated weight of the 399 particles used for optimization and performance assessment were below $10 \mu \mathrm{g}$ with the 400 exception of uPVC particles and were even below $1 \mu \mathrm{g}$ for some polymers (i.e. PS and PP). 401 Furthermore, in previous works, Py-GC/MS was successfully applied to identify particles 402 weighting $20 \mu \mathrm{g}$ [24] and below $10 \mu \mathrm{g}$ [22]. Limit of detection expressed in $\mu \mathrm{g}$ were low and 
403 demonstrate that this method is applicable to very small and light particles. In addition to

404 LOD in $\mu \mathrm{m}$, theoretical identifiable size (in $\mu \mathrm{m}$ ) were calculated for MP in form of spheres, 405 fibers and fragments for all 8 polymer tested in the present study (Table 3). Those theoretical 406 minimal identifiable sizes were calculated using the LOD expressed in mass, polymer density 407 and equation (1-3) (see Electronic Supplementary Material Weight Estimation). For spheres, 408 all identifiable size were below $60 \mu \mathrm{m}$ in diameter, for fibers of $20 \mu \mathrm{m}$ of diameter length size 409 varied from $9.2 \mu \mathrm{m}$ to $366.6 \mu \mathrm{m}$ and for fragment all length size were below $50 \mu \mathrm{m}$ (Table 3 ). 410 Here, these theoretical sizes showed that fiber are the MP form with the longest size 411 identifiable with the optimized Py-GC/MS. Indeed, fibers are long but thin resulting in an 412 important considered size (as the longest size was selected) with a low estimated weight. 413 Moreover, as Py-GC/MS rely on particles weight, it is an important parameter to master in 414 MP research.

415 MP are commonly defined as plastic particles smaller than $5 \mathrm{~mm}$ [7]. However, recently, 416 some studies argue that plastic particles should be described using another parameter [42, 43]. 417 Here, as stated by Simon et al, [43], weight was chosen as an additional parameter to record 418 during MP studies. Indeed, plastic including MP are three dimensions particles, the 419 description of such particles accordingly to their longest size is problematic and could not be 420 adequate for data interpretations [43]. Actually, it is easy to visualize that there is an 421 important difference in weight for a fiber measuring $500 \mu \mathrm{m}$ in its longest size with few 422 microns of diameters and a cubic fragment measuring $500 \mu \mathrm{m}$ for all its side. This difference 423 in weight could also have different adverse effect when these particles are, for example, 424 ingested by organisms. In addition, plastic emissions to the Oceans are estimate in weight [3] 425 and determining MP weight could help for further estimation of MP source and quantities in 426 the Oceans. In the present study, limit of detection of the optimized Py-GC/MS were 427 estimated in $\mu \mathrm{g}$ because this technique is dependent on the particle weight and not their size. 
Moreover, in other studies using thermal analyses, MP could be directly quantified in samples as previously demonstrated $[22,44]$. Nevertheless, in the present study such quantification was not the purpose of the work. For further studies, MP weight should be estimated using weighting if possible or using volume calculation followed by weight estimation using a range of polymer density or using density found in the literature, as done by Simon et al, [43].

433 However, before being submitted to Py-GC/MS analysis, particles have to be handled with tweezers and placed in an analysis cup. The main limitation with the presented method is the "handibility" of the particles. Below $50 \mu \mathrm{m}$ it is very difficult to manipulate the particles as some particles may easily "fly away". Here, the device is not the limiting element whereas the operator is as almost all theoretical identifiable sizes are below $50 \mu \mathrm{m}$. Moreover, for application on unknown particles, the highest LOD have to be considered to ensure accurate identification. Consequently and to date, the effective lowest size for plastic identification with this Py-GC/MS method, using particle handling, was evaluated at $50 \mu \mathrm{m}$.

441 Nevertheless, Py-GC/MS has been used to identify nanometric size scale plastic from bulk 442 sample [31]. This approach was made possible as it did not use direct particles handling due 443 to their sizes and because a data statistical treatment was applied after acquisition of 444 pyrograms [31]. If direct handling of particles is not use, Py-GC/MS could be applied to 445 identify smaller plastic particles. Indeed, the use of flow-cytometry using sorting [45] could 446 be used to place potential MP in analysis cup. Flow cytometry in combination with a camera 447 and a cell sorter have been used to detect MP [46]. Another technique could be the use of 448 staining techniques like Nile red [47-49] before Py-GC/MS analysis. Indeed, stained particles 449 could be introduced in analysis cup directly with the filter, for example. Moreover, the use of 450 fixing solution to trap MP could also be a solution to isolate this particle and placing them in 451 the analysis cup. However, potential interference of these solutions be carefully controlled 
452 before to be employed in routine. With Py-GC/MS, development to isolate particles should be

453 performed to enhance particle handling and to ensure that the device is the only limitation.

\section{$454 \quad$ 3.3. Method comparison}

455 Here particles were collected by hand on a local beach. Particles used to compare 456 identifications between $\mu$-Raman and Py-GC/MS were diverse in shapes and colors. The most 457 common shape was fragments (21), followed by pellets (14), filaments (6), beads (5) and 458 foams (4). Concerning particles color, green was the most common (8), followed by orange 459 (7), blue (7), transparent (6), red (5), yellow (4), white (3), black (3), grey (3), purple (3), and 460 pink (1).

461 Only forty out of fifty particles were identified with $\mu$-Raman as plastic particles. From the 462 ten particles not identified, four were identified as pigments containing particles (Cobalt and 463 copper phthalocyanine and Mortoperm blue). Among the 40 identified particles, there was: 464 PE (22), PP (11), PS (3), PE-PP copolymer (3), and polyamide (1) (Fig 3). 

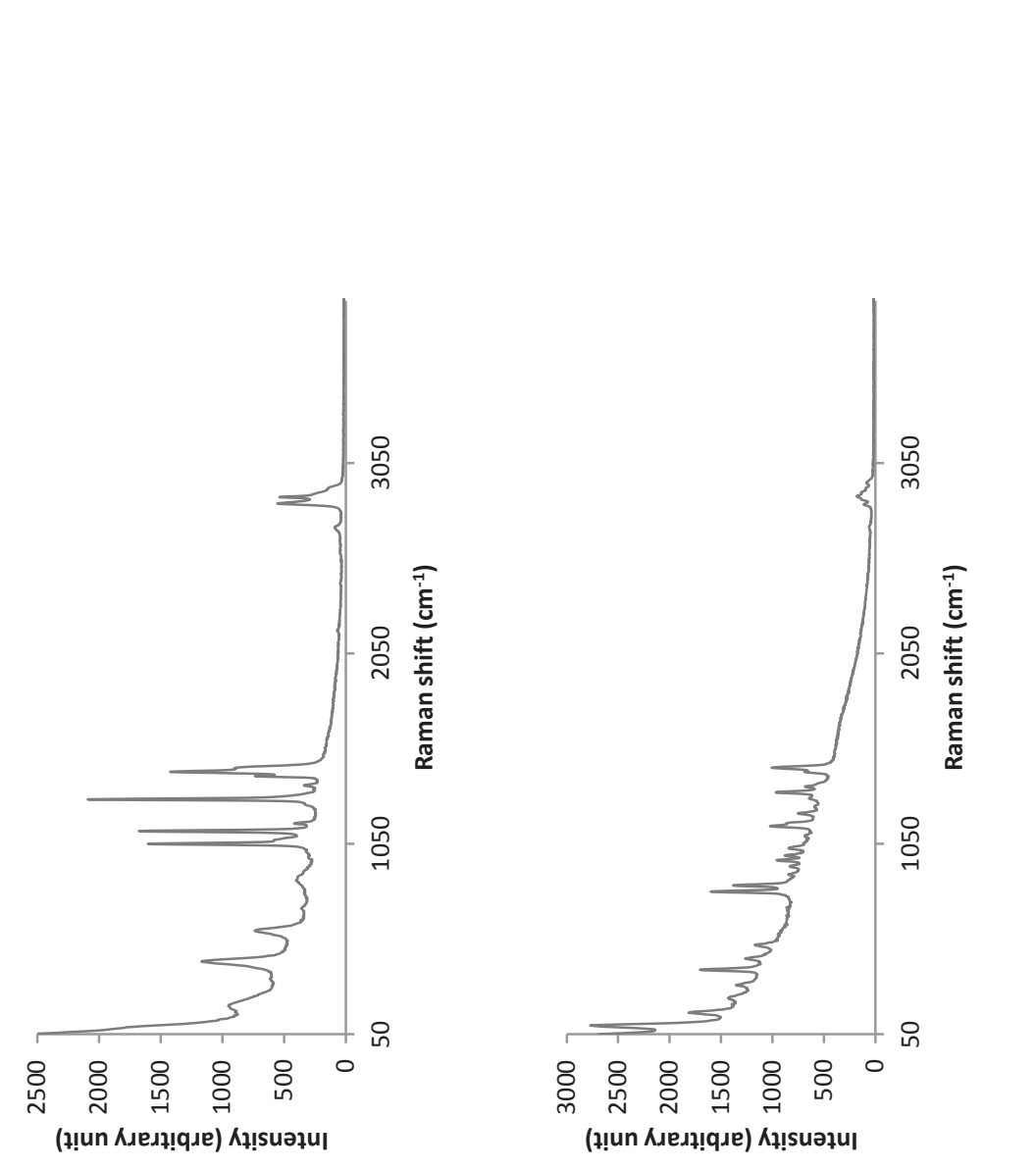

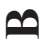
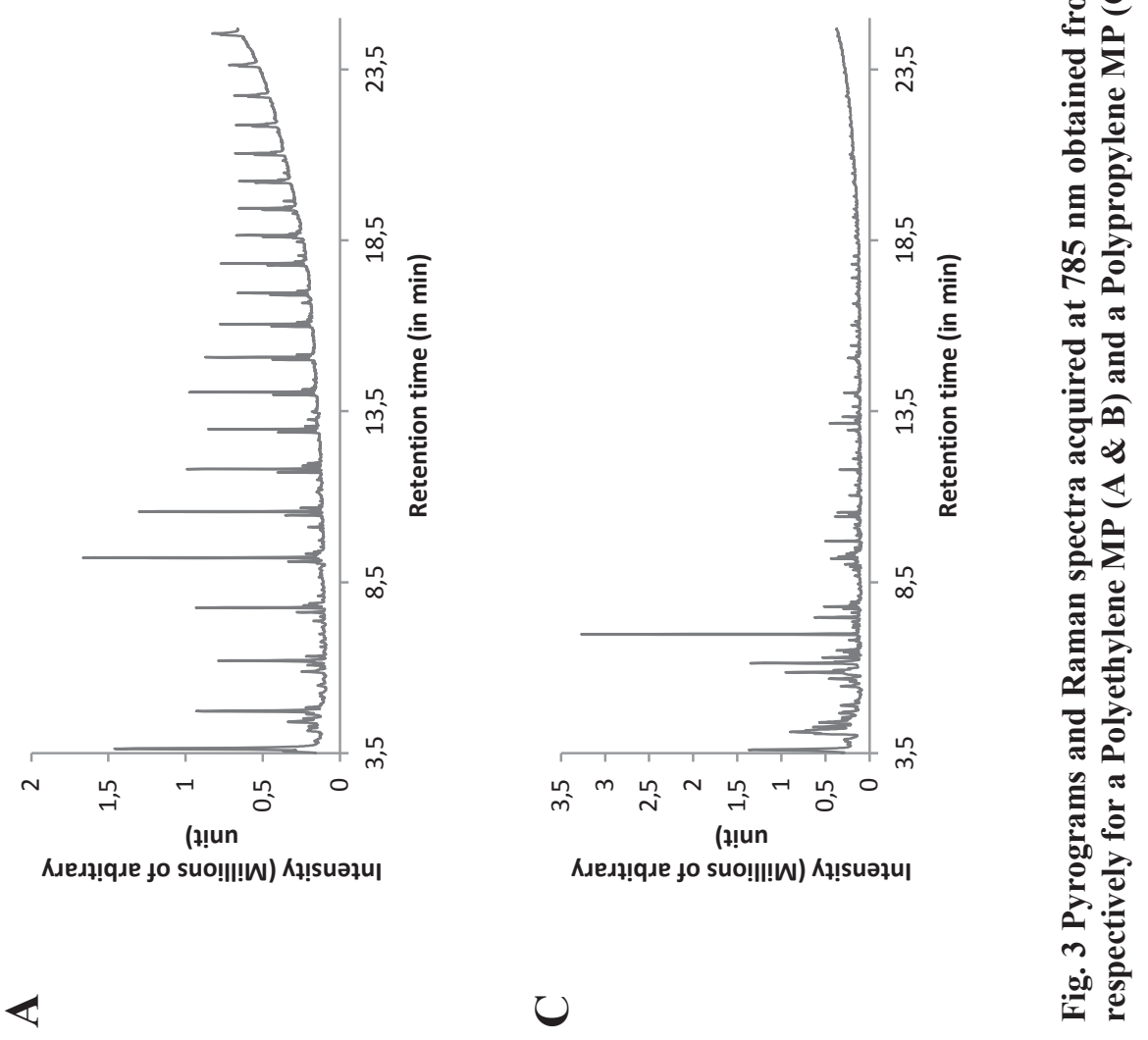

绎导字 
The optimized Py-GC/MS method also identified all the 40 particles. Thirty seven particles

469 (92 \%) were identified as they were after $\mu$-Raman analysis. Py-GC/MS led to results with a 470 finer identification, two PP particles being identified as PE-PP copolymer. Moreover, the 471 particle identified as polyamide with $\mu$-Raman was identified as a copolymer made of PE, PP 472 and PA-6 (see Electronic Supplementary Material Figure S13). The optimized Py-GC/MS 473 method identified $100 \%$ of the 40 previously identified particles with $\mu$-Raman as plastic and 474 demonstrated that this method is reliable for MP identification.

475 Some particles were not identified with $\mu$-Raman spectroscopy or were identified as 476 pigments. Pigment containing particles identification were also obtained in previous studies 477 on MP from water samples or marine organisms [16, 26-28]. Misidentification could occur for 478 these pigmented particles pigments due to an overlaying of the polymer signal by the additive $479[11,50]$. Although some pigments are synthetic molecules, it could indicate a synthetic origin 480 but those particles could not be classified as plastic with certainty leading to potential 481 underestimation in field studies. Indeed some particle containing pigments could simply be 482 colorful paint particles as demonstrated by Imhof et al, [50]. Out of the 6 not identified 483 particles, 3 were discolored pellets. Discoloration indicates that pellets had a higher residence 484 time in the environment [51]. Additionally, Py-GC/MS could also be complementary to FTIR 485 to identified MP in field studies, as recently demonstrated [52]. Indeed, using FTIR polymer 486 signal could be overlap by some plastic additives included and identification could be 487 disturbed [53, 54]. In a recent study, Elert et al. [55] demonstrated that depending on the 488 require information on MP information, i.e. quantification or identification of polymers, the 489 appropriate technique should be used but the authors also indicated that identifications should 490 be used in complementarity. Raman, FTIR and Py-GC/MS are, to date, the major 491 identification techniques used in MP studies and those techniques are all complementary. 
492 Then, the unidentified particles with $\mu$-Raman spectroscopy were analyzed by Py-GC/MS and 493 included in the application section (cf. 3.4).

\subsection{Application: identification of unknown particles}

495 On the sixty analyzed particles by Py-GC/MS, twenty (16 particles from bivalves and 4 from 496 beach samples) formely identified as pigment containing particles by $\mu$-Raman were 497 processed by Py-GC/MS. All twenty particles were fragments with blue the dominant color 498 with only one being green. Py-GC/MS identified 14 pigment particles as plastic polymers (70 $499 \%), 4$ pigment particles as plastic polymers with some uncertainty (20\%) and 2 particles were 500 not identified (10\% - Fig. 4). PS was the most common identified polymer (13 particles out of 501 14) with one particle identified as a copolymer of PS and PMMA. Moreover, particles 502 identified with uncertainty displayed characteristic compounds of PS but with low intensity. 503 Here, Py-GC/MS identified $70 \%$ of particles that were previously identified as pigment 504 containing particles using $\mu$-Raman. Moreover, $\mu$-Raman only identified presence of the 505 pigments nature as it overlaps with polymer signals, while Pyrolysis only allow to identify the 506 native plastic polymer. Despite an effective lowest size of $50 \mu \mathrm{m}$, due to handling issue, being 50710 to 50 times higher than the lowest size respectively analyzable by FTIR or $\mu$-Raman 508 spectroscopy, respectively, the Py-GC/MS method is still competitive and complementary. 509 Indeed, as it allows (i) the full identification of pigments and some fibers and (ii) could be 510 combined with improved separation methods to retrieve smaller particles. Here, Py-GC/MS 511 could be used as a complementary identification method after $\mu$-Raman spectroscopy. 


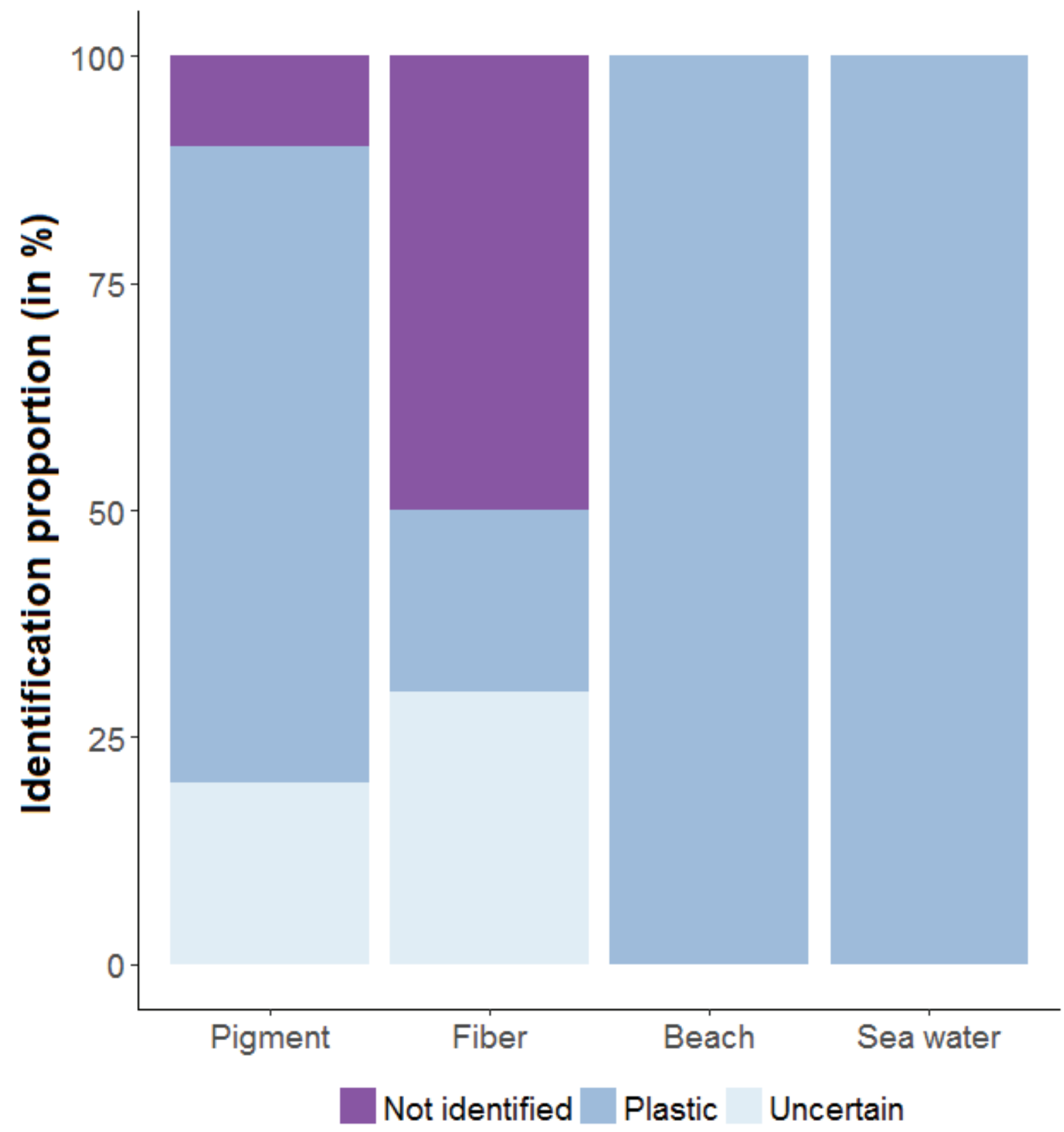

Fig. 4 Sample proportion for each identification class obtained after Py-GC/MS for particles previously identified as pigment $(n=20)$ by $\mu$ Raman, fibers $(n=10)$ and particles collected on a beach $(n=6)$ and in surface sea water of the Bay of Brest $(n=24)$. Not identified correspond to particles with low or no discernible signal, Uncertain to identification as plastic with some uncertainty and Plastic to identification with accurate polymer attribution

518 Out of the 10 fibers extracted from bivalves, 7 were blue, 2 were black, and 1 was red. For

519 fibers, identification was achieved having 2 fibers identified as PE and Polyacrylonitrile

520 (PAN). Fibers made of PAN, PE and potentially PET were identify and such polymer are

521 commonly used in the textile industry [56] and are found in wastewater treatment plants after

522 washing machine [57]. Three fibers were identified as plastic polymer with some uncertainty 
and 5 fibers were not identified due to low or absent signal (Fig. 5). Uncertain identification for fibers comprised $1 \mathrm{PE}$ and 2 PET. Fibers identification was tough. Indeed, only $20 \%$ of the analyzed fibers were correctly identified. As fibers are long and thin, they are lighter in comparison with fragment. As Py-GC/MS rely more on particle weight than on their size, low weight could result in uncertainity with identifications, as previously observed for fibers in a study conducted by Hendrickson et al, [24]. To improve fibers and small particles identification, a solution could be the use of single ion monitoring (SIM) which target selected ion $(\mathrm{m} / \mathrm{z})$ allowing to decrease the LOD.

Out of the 30 others particles collected at sea-surface or in beach sediment, fragments (10) were the most common particles followed by foams (6), filaments (5), pellets (4), films (4), and beads (1). Regarding particles color: white was the dominant color (8) followed by blue (6), orange (5), transparent (5), green (3), red (1), black (1), and yellow (1). Particles were all identified as plastic with no uncertainty (Fig. 5) however it is important to indicate that the particule used in this section were large MP cut $(c a .200 \mu \mathrm{m})$ to be introduced in an analysis cup. PE (14) was the most common polymer followed by PP (9) and PS (4). Other polymers including PE-PP copolymer, Chlorinated PE (CPE), and Acrylonitrile-butadiene-styrene copolymer (ABS) were each found only once. Py-GC/MS provide good identification with similarity percentage above $80 \%$. The differentiation between PS and ABS remained difficult as both polymers are made with styrene which is the major characteristic compounds of their pyrograms [32, 33]. ABS reference presented an interesting characteristic compound: 1Naphthalenecarbonitrile. This compound was only present in ABS reference pyrogram. Differentiation was made using this compound and tracking it in the pyrogram using its major ion: $153 \mathrm{~m} / \mathrm{z}$. Polymers identified i.e. PE, PP and PS are commonly reported on the beach [58] and in sea-surface water [38]. 


\section{Conclusion}

The present work described an in-depth optimization of a Py-GC/MS method to identify MP followed by an efficiency assessment of its performance and a comparison with Raman spectroscopic approach. In addition, to evaluate the robustness of the optimized Py-GC/MS method to identify MP, it was applied on samples from different matrices: bivalve, beach and sea-water surface. Optimization demonstrated that increasing pyrolysis temperature up to 700 ${ }^{\circ} \mathrm{C}$ in combination with a split ratio of 5 and an injector temperature set at $300{ }^{\circ} \mathrm{C}$ improved signal detection. Then, performance assessment demonstrated that if signal vary over time, such variation had no impact on MP identification. This method is validated on qualitative data but not on quantitative one due to RSD value above $20 \%$ for repeatability and intermediate precision.

The optimized Py-GC/MS has some advantages in comparison with other MP identification methods. Firstly, Py-GC/MS is a complementary method to spectroscopy approaches. Indeed, in the present study Py-GC/MS enable identification of pigment containing particles right after $\mu$-Raman analysis. Moreover Py-GC/MS identified co-polymer like PE-PP or PE-PPPA6 which could be difficult to identify with $\mu$-Raman without chemometrics approach. Secondly, up to date, Py-GC/MS identification of plastic particles cannot be done below 50 $\mu \mathrm{m}$ (longest size) not because of LOD but due to operator handling issues. A better way, like the introduction of a piece of filter on which particles are into the analysis cup, should be developed in order to avoid this limiting step. However, Py-GC/MS could be used to identify smaller particles, like nanoplastics as already demonstrated. By resolving this handling issue, LOD calculation demonstrated that this method could identify isolated MP weighting below 1 $\mu$ g. In addition, another strategy that can be considered to lower the LOD for this Py-GC/MS method is the use of SIM. To get identification on MP polluting from both freshwater and marine environment, the use of Py-GC/MS should be better considered as this method prove 
572 to be efficient in identifying MP from various matrices. In an effort to standardize the MP 573 analysis workflow, this method could be implemented either on its own or after FTIR or 574 Raman to confirm some identification or to circumvent unsuccessful spectroscopy 575 identification. Finally, MP mass should be evaluated in MP studies to try to standardized 576 leading to better comparison of MP contamination between studies. 


\section{Acknowledgments}

579 Ludovic Hermabessiere is grateful to the Hauts-de-France Region and ANSES (French

580 Agency for Food, Environmental and Occupational Health \& Safety) for the financial support 581 of his $\mathrm{PhD}$. Maria Kazour is financially supported by a $\mathrm{PhD}$ fellowship from the National 582 Council for Scientific Research (Lebanon) and Université du Littoral Côte d'Opale (France). 583 This paper has been funded by the French National Research Agency (ANR) (ANR-15-CE34584 0006-02), as part of the Nanoplastics project and also by the French government and the 585 Hauts-de-France Region in the framework of the project CPER 2014-2020 MARCO.

This is a post-peer-review, pre-copyedit version of an article published in Analytical and

587 Bioanalytical Chemistry. The final authenticated version is available online at: 588 https://doi.org/10.1007/s00216-018-1279-0

\section{Compliance with Ethical Standards}

590 Conflict of Interest: Authors declare no conflict of interest.

\section{References}

592 1. Thompson, R.C., S.H. Swan, C.J. Moore, and F.S. vom Saal, 2009. Our plastic age. 593 Philosophical Transactions of the Royal Society B: Biological Sciences. 364, 1973594 1976. doi: 10.1098/rstb.2009.0054

2. PlasticsEurope, 2018. Plastics - the Facts 2017: An analysis of European plastics production, demand and waste data. Available on: http://www.plasticseurope.fr/Document/plastics---the-facts-2017.aspx?FolID=2, Accessed on: 01/29/2018

3. Jambeck, J.R., R. Geyer, C. Wilcox, T.R. Siegler, M. Perryman, A. Andrady, R. Narayan, and K.L. Law, 2015. Plastic waste inputs from land into the ocean. Science. 347, 768-771. doi: 10.1126/science.1260352

4. Cózar, A., F. Echevarría, J.I. González-Gordillo, X. Irigoien, B. Úbeda, S. HernándezLeón, Á.T. Palma, S. Navarro, J. García-de-Lomas, A. Ruiz, M.L. Fernández-dePuelles, and C.M. Duarte, 2014. Plastic debris in the open ocean. Proceedings of the National Academy of Sciences. 111, 10239-10244. doi: 10.1073/pnas.1314705111

5. Eriksen, M., L.C. Lebreton, H.S. Carson, M. Thiel, C.J. Moore, J.C. Borerro, F. Galgani, P.G. Ryan, and J. Reisser, 2014. Plastic pollution in the world's oceans: more 
than 5 trillion plastic pieces weighing over 250,000 tons afloat at sea. PloS one. 9, e111913.

6. van Sebille, E., C. Wilcox, L. Lebreton, N. Maximenko, B.D. Hardesty, J.A. van Franeker, M. Eriksen, D. Siegel, F. Galgani, and K.L. Law, 2015. A global inventory of small floating plastic debris. Environmental Research Letters. 10, 124006.

7. Arthur, C., J. Baker, and H. Bamford, 2009. International Research Workshop on the Occurrence, Effects, and Fate of Microplastic Marine Debris. NOAA Technical Memorandum NOS-OR\&R-30.

8. Li, W.C., H.F. Tse, and L. Fok, 2016. Plastic waste in the marine environment: A review of sources, occurrence and effects. Science of The Total Environment. 566567, 333-349. doi: 10.1016/j.scitotenv.2016.05.084

9. Horton, A.A., A. Walton, D.J. Spurgeon, E. Lahive, and C. Svendsen, 2017. Microplastics in freshwater and terrestrial environments: Evaluating the current understanding to identify the knowledge gaps and future research priorities. Science of The Total Environment. 586, 127-141. doi: 10.1016/j.scitotenv.2017.01.190

10. Imhof, H.K., J. Schmid, R. Niessner, N.P. Ivleva, and C. Laforsch, 2012. A novel, highly efficient method for the separation and quantification of plastic particles in sediments of aquatic environments. Limnology and Oceanography: Methods. 10, 524537. doi: 10.4319/lom.2012.10.524

11. Lenz, R., K. Enders, C.A. Stedmon, D.M.A. Mackenzie, and T.G. Nielsen, 2015. A critical assessment of visual identification of marine microplastic using Raman spectroscopy for analysis improvement. Marine Pollution Bulletin. 100, 82-91. doi: 10.1016/j.marpolbul.2015.09.026

12. Shim, W.J., S.H. Hong, and S.E. Eo, 2017. Identification methods in microplastic analysis: a review. Analytical Methods. 9, 1384-1391. doi: 10.1039/C6AY02558G

13. CAMPUS, 2018. Available on: https://www.campusplastics.com/campus/list, Accessed on: 01/26/2018

14. Remy, F., F. Collard, B. Gilbert, P. Compère, G. Eppe, and G. Lepoint, 2015. When Microplastic Is Not Plastic: The Ingestion of Artificial Cellulose Fibers by Macrofauna Living in Seagrass Macrophytodetritus. Environmental Science \& Technology. 49, 11158-11166. doi: 10.1021/acs.est.5b02005

15. Rocha-Santos, T. and A.C. Duarte, 2015. A critical overview of the analytical approaches to the occurrence, the fate and the behavior of microplastics in the environment. Trends in Analytical Chemistry. 65, 47-53. doi: 10.1016/j.trac.2014.10.011

16. Frère, L., I. Paul-Pont, J. Moreau, P. Soudant, C. Lambert, A. Huvet, and E. Rinnert, 2016. A semi-automated Raman micro-spectroscopy method for morphological and chemical characterizations of microplastic litter. Marine Pollution Bulletin. 113, 461468. doi: 10.1016/j.marpolbul.2016.10.051

17. Oßmann, B.E., G. Sarau, S.W. Schmitt, H. Holtmannspötter, S.H. Christiansen, and W. Dicke, 2017. Development of an optimal filter substrate for the identification of small microplastic particles in food by micro-Raman spectroscopy. Analytical and Bioanalytical Chemistry. 409, 4099-4109. doi: 10.1007/s00216-017-0358-y

18. Phuong, N.N., A. Zalouk-Vergnoux, A. Kamari, C. Mouneyrac, F. Amiard, L. Poirier, and F. Lagarde, 2017. Quantification and characterization of microplastics in blue mussels (Mytilus edulis): protocol setup and preliminary data on the contamination of the French Atlantic coast. Environmental Science and Pollution Research, 1-10. doi: $10.1007 / \mathrm{s} 11356-017-8862-3$ 
663

664

665

666

667

668

669

670

671

672

673

674

675

676

677

678

679

680

681

682

683

684

685

686

687

688

689

690

691

692

693

694

695

696

697

698

699

700

701

702

703

704

19. Dekiff, J.H., D. Remy, J. Klasmeier, and E. Fries, 2014. Occurrence and spatial distribution of microplastics in sediments from Norderney. Environmental Pollution. 186, 248-256. doi: 10.1016/j.envpol.2013.11.019

20. Fries, E., J.H. Dekiff, J. Willmeyer, M.-T. Nuelle, M. Ebert, and D. Remy, 2013. Identification of polymer types and additives in marine microplastic particles using pyrolysis-GC/MS and scanning electron microscopy. Environmental Science: Processes \& Impacts. 15, 1949-1956. doi: 10.1039/C3EM00214D

21. Nuelle, M.-T., J.H. Dekiff, D. Remy, and E. Fries, 2014. A new analytical approach for monitoring microplastics in marine sediments. Environmental Pollution. 184, 161169. doi: 10.1016/j.envpol.2013.07.027

22. Fischer, M. and B.M. Scholz-Böttcher, 2017. Simultaneous Trace Identification and Quantification of Common Types of Microplastics in Environmental Samples by Pyrolysis-Gas Chromatography-Mass Spectrometry. Environmental Science \& Technology. 51, 5052-5060. doi: 10.1021/acs.est.6b06362

23. Fabbri, D., D. Tartari, and C. Trombini, 2000. Analysis of poly(vinyl chloride) and other polymers in sediments and suspended matter of a coastal lagoon by pyrolysisgas chromatography-mass spectrometry. Analytica Chimica Acta. 413, 3-11. doi: 10.1016/S0003-2670(00)00766-2

24. Hendrickson, E., E.C. Minor, and K. Schreiner, 2018. Microplastic abundance and composition in western Lake Superior as determined via microscopy, Pyr-GC/MS, and FTIR. Environmental Science \& Technology. 52, 1787-1796. doi: 10.1021/acs.est.7b05829

25. Ceccarini, A., A. Corti, F. Erba, F. Modugno, J. La Nasa, S. Bianchi, and V. Castelvetro, 2018. The hidden microplastics. New insights and figures from the thorough separation and characterization of microplastics and of their degradation byproducts in coastal sediments. Environmental Science \& Technology. doi: $10.1021 /$ acs.est.8b01487

26. Van Cauwenberghe, L., M. Claessens, M.B. Vandegehuchte, and C.R. Janssen, 2015. Microplastics are taken up by mussels (Mytilus edulis) and lugworms (Arenicola marina) living in natural habitats. Environmental Pollution. 199, 10-17. doi: 10.1016/j.envpol.2015.01.008

27. Van Cauwenberghe, L. and C.R. Janssen, 2014. Microplastics in bivalves cultured for human consumption. Environmental Pollution. 193, 65-70. doi: 10.1016/j.envpol.2014.06.010

28. Schymanski, D., C. Goldbeck, H.-U. Humpf, and P. Fürst, 2018. Analysis of microplastics in water by micro-Raman spectroscopy: Release of plastic particles from different packaging into mineral water. Water Research. 129, 154-162. doi: 10.1016/j.watres.2017.11.011

29. Li, J., H. Liu, and J. Paul Chen, 2018. Microplastics in freshwater systems: A review on occurrence, environmental effects, and methods for microplastics detection. Water Research. 137, 362-374. doi: 10.1016/j.watres.2017.12.056

30. Ivleva, N.P., A.C. Wiesheu, and R. Niessner, 2016. Microplastic in Aquatic Ecosystems. Angewandte Chemie International Edition. 56, 1720-1739. doi: 10.1002/anie.201606957

31. Ter Halle, A., L. Jeanneau, M. Martignac, E. Jardé, B. Pedrono, L. Brach, and J. Gigault, 2017. Nanoplastic in the North Atlantic Subtropical Gyre. Environmental Science \& Technology. 51, 13689-13697. doi: 10.1021/acs.est.7b03667

32. Tsuge, S., H. Ohtani, and C. Watanabe, Pyrolysis-GC/MS Data Book of Synthetic Polymers. 2011: Elsevier. 390. 
33. Kusch, P., Application of Pyrolysis-Gas Chromatography/Mass Spectrometry (Py$G C / M S$ ), in Characterization and Analysis of Microplastics, T. Rocha-Santos and A. Duarte, Editors. 2016, Elsevier. p. 306.

34. van Den Dool, H. and P.D. Kratz, 1963. A generalization of the retention index system including linear temperature programmed gas-liquid partition chromatography. Journal of Chromatography A. 11, 463-471. doi: 10.1016/S0021-9673(01)80947-X

35. Dehaut, A., A.-L. Cassone, L. Frère, L. Hermabessiere, C. Himber, E. Rinnert, G. Rivière, C. Lambert, P. Soudant, A. Huvet, G. Duflos, and I. Paul-Pont, 2016. Microplastics in seafood: Benchmark protocol for their extraction and characterization. Environmental Pollution. 215, 223-233. doi: 10.1016/j.envpol.2016.05.018

36. International Organization for Standardization (ISO), 1994. 5725-3: 1994, Accuracy (trueness and precision) of measurement methods and results-Part 3: Intermediate measures of the precision of a standard measurement method. International Organization for Standardization, Geneva.

37. Caporal-Gautier, J., M. Nivet J, P. Algranti, M. Guilloteau, M. Histe, M. Lallier, J. N'Guyen-Huu J, and R. Russotto, 1992. Guide de validation analytique. Rapport d'une commission SFSTP. I : Méthodologie. STP pharma pratiques. 2, 205-226.

38. Frère, L., I. Paul-Pont, E. Rinnert, S. Petton, J. Jaffré, I. Bihannic, P. Soudant, C. Lambert, and A. Huvet, 2017. Influence of environmental and anthropogenic factors on the composition, concentration and spatial distribution of microplastics: A case study of the Bay of Brest (Brittany, France). Environmental Pollution. 225, 211-222. doi: https://doi.org/10.1016/j.envpol.2017.03.023

39. R Core Team, 2015. R: A language and environment for statistical computing. Vienna, Austria; 2014. Available on: http://www.R-project.org, Accessed on: 10/15/2015

40. De Mendiburu, F., 2014. Agricolae: statistical procedures for agricultural research. R package version.

41. McGuffin, V.L., Theory of chromatography, in Journal of Chromatography Library. 2004, Elsevier. p. 1-93.

42. Filella, M., 2015. Questions of size and numbers in environmental research on microplastics: methodological and conceptual aspects. Environmental Chemistry. 12, 527-538. doi: 10.1071/EN15012

43. Simon, M., N. van Alst, and J. Vollertsen, 2018. Quantification of microplastic mass and removal rates at wastewater treatment plants applying Focal Plane Array (FPA)based Fourier Transform Infrared (FT-IR) imaging. Water Research. 142, 1-9. doi: 10.1016/j.watres.2018.05.019

44. Dümichen, E., A.-K. Barthel, U. Braun, C.G. Bannick, K. Brand, M. Jekel, and R. Senz, 2015. Analysis of polyethylene microplastics in environmental samples, using a thermal decomposition method. Water Research. 85, 451-457. doi: 10.1016/j.watres.2015.09.002

45. Ibrahim, S.F. and G. van den Engh, Flow Cytometry and Cell Sorting, in Cell Separation: Fundamentals, Analytical and Preparative Methods, A. Kumar, I.Y. Galaev, and B. Mattiasson, Editors. 2007, Springer Berlin Heidelberg: Berlin, Heidelberg. p. 19-39.

46. Sgier, L., R. Freimann, A. Zupanic, and A. Kroll, 2016. Flow cytometry combined with viSNE for the analysis of microbial biofilms and detection of microplastics. Nature communications. 7, 11587.

47. Shim, W.J., Y.K. Song, S.H. Hong, and M. Jang, 2016. Identification and quantification of microplastics using Nile Red staining. Marine Pollution Bulletin. 113, 469-476. doi: 10.1016/j.marpolbul.2016.10.049 
48. Maes, T., R. Jessop, N. Wellner, K. Haupt, and A.G. Mayes, 2017. A rapid-screening approach to detect and quantify microplastics based on fluorescent tagging with Nile Red. Scientific Reports. 7, 44501. doi: 10.1038/srep44501

49. Erni-Cassola, G., M.I. Gibson, R.C. Thompson, and J.A. Christie-Oleza, 2017. Lost, but Found with Nile Red: A Novel Method for Detecting and Quantifying Small Microplastics (1 $\mathrm{mm}$ to $20 \mu \mathrm{m}$ ) in Environmental Samples. Environmental Science \& Technology. 51, 13641-13648. doi: 10.1021/acs.est.7b04512

50. Imhof, H.K., C. Laforsch, A.C. Wiesheu, J. Schmid, P.M. Anger, R. Niessner, and N.P. Ivleva, 2016. Pigments and plastic in limnetic ecosystems: A qualitative and quantitative study on microparticles of different size classes. Water Research. 98, 6474. doi: 10.1016/j.watres.2016.03.015

51. Endo, S., R. Takizawa, K. Okuda, H. Takada, K. Chiba, H. Kanehiro, H. Ogi, R. Yamashita, and T. Date, 2005. Concentration of polychlorinated biphenyls (PCBs) in beached resin pellets: Variability among individual particles and regional differences. Marine Pollution Bulletin. 50, 1103-1114. doi: 10.1016/j.marpolbul.2005.04.030

52. Käppler, A., M. Fischer, B.M. Scholz-Böttcher, S. Oberbeckmann, M. Labrenz, D. Fischer, K.-J. Eichhorn, and B. Voit, 2018. Comparison of $\mu$-ATR-FTIR spectroscopy and py-GCMS as identification tools for microplastic particles and fibers isolated from river sediments. Analytical and Bioanalytical Chemistry. doi: 10.1007/s00216-018$1185-5$

53. Tabb, D.L. and J.L. Koenig, 1975. Fourier Transform Infrared Study of Plasticized and Unplasticized Poly(vinyl chloride). Macromolecules. 8, 929-934. doi: 10.1021/ma60048a043

54. González, N. and M.J. Fernández-Berridi, 2006. Application of Fourier transform infrared spectroscopy in the study of interactions between PVC and plasticizers: PVC/plasticizer compatibility versus chemical structure of plasticizer. Journal of Applied Polymer Science. 101, 1731-1737. doi: doi:10.1002/app.23381

55. Elert, A.M., R. Becker, E. Duemichen, P. Eisentraut, J. Falkenhagen, H. Sturm, and U. Braun, 2017. Comparison of different methods for MP detection: What can we learn from them, and why asking the right question before measurements matters? Environmental Pollution. 231, 1256-1264. doi: 10.1016/j.envpol.2017.08.074

56. Napper, I.E. and R.C. Thompson, 2016. Release of synthetic microplastic plastic fibres from domestic washing machines: Effects of fabric type and washing conditions. Marine Pollution Bulletin. 112, 39-45. doi: https://doi.org/10.1016/j.marpolbul.2016.09.025

57. Browne, M.A., P. Crump, S.J. Niven, E. Teuten, A. Tonkin, T. Galloway, and R. Thompson, 2011. Accumulation of Microplastic on Shorelines Woldwide: Sources and Sinks. Environmental Science \& Technology. 45, 9175-9179. doi: 10.1021/es201811s

58. Lots, F.A.E., P. Behrens, M.G. Vijver, A.A. Horton, and T. Bosker, 2017. A largescale investigation of microplastic contamination: Abundance and characteristics of microplastics in European beach sediment. Marine Pollution Bulletin. 123, 219-226. doi: https://doi.org/10.1016/j.marpolbul.2017.08.057 